\title{
EMOTIONS EXPERIENCED BY LEARNERS AND THEIR DEVELOPMENT THROUGH COMMUNICATION WITH THE TUTOR-COUNSELLOR
}

Michail Kalogiannakis [mkalogian@edc.uoc.gr], University of Crete, Faculty of Education, Department of Preschool Education, Sotiris Touvlatiis [stouvlatiis@gmail.com], Secondary Education Teacher, Kavala, Greece

\begin{abstract}
The effective communication between the learners and the tutor-counsellor has been proved to significantly promote the positive emotions, reduce the negative ones and reinforce the learners' participation in a distance learning program. The main purpose of our research is to investigate the emotions experienced by the learners of the Hellenic Open University (HOU) and how these emotions may vary through interaction with the tutor-counsellor. In order to carry out the research, a combination of quantitative and qualitative methods was implemented. Data collection was performed via an anonymous questionnaire and semi-structured interviews. The sample of the research consisted of undergraduate and post-graduate students of the HOU. Our findings confirm the dominant place occupied by emotions in the learning process, a place that has been until recently entirely attributed to reason, while highlighting the communicative and supportive role to be taken by the tutor-counsellor in distance learning programs.
\end{abstract}

\section{Abstract in Greek}

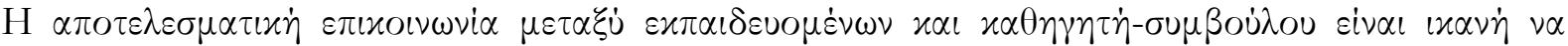

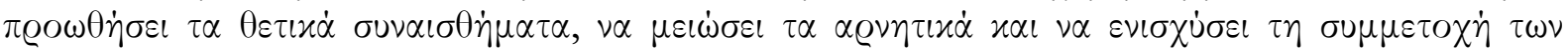

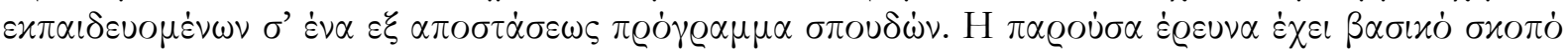

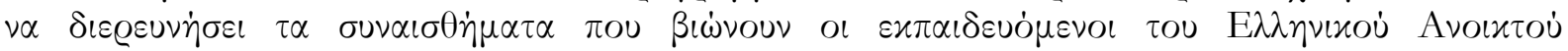

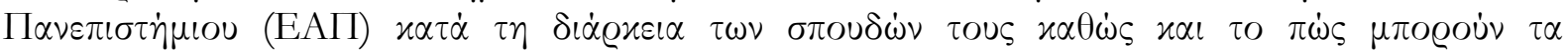

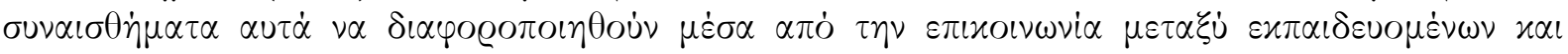

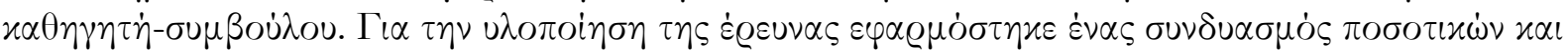

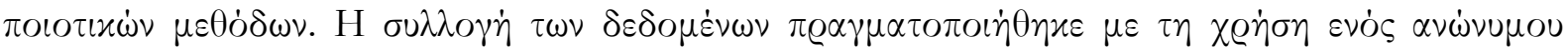

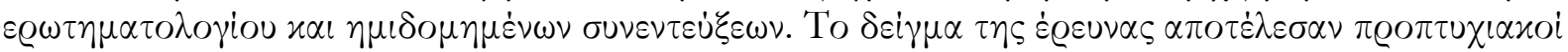

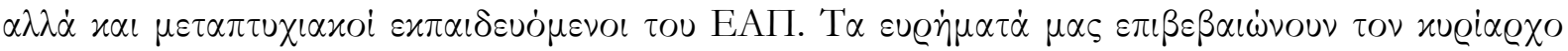

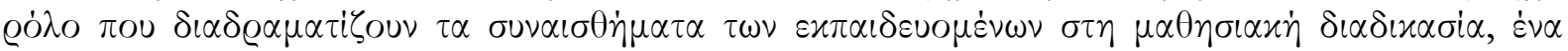

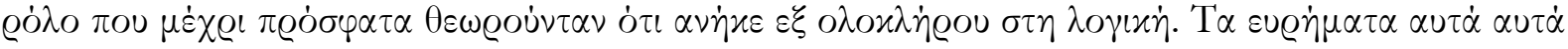

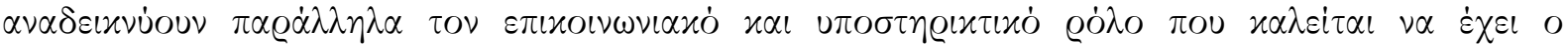
$\varkappa \alpha \theta \eta \gamma \eta \tau \dot{\eta} \varsigma-\sigma \dot{\mu} \mu \beta O u \lambda \circ \varsigma \sigma \tau \eta \nu \varepsilon \xi \alpha \pi O \sigma \tau \dot{\alpha} \sigma \varepsilon \omega \varsigma \varepsilon \varkappa \pi \alpha i \delta \varepsilon v \sigma \eta$.

Keywords: distance learning, learners' emotions, tutor-counsellor, collaboration, interaction, support.

\section{Introduction}

The field of distance learning has been exponentially extending worldwide in all levels of education (Vrasidas \& Zembylas, 2003; Holcomb, King \& Brown, 2004; Jones \& Issroff, 2005). One of the major challenges encountered is the lack of direct contact between the learners and the tutor-counsellor (Berenson, Boyles \& Weaver, 2008). The traditional education involves faceto-face communication, eye contact, tone of voice, posture and facial expressions, however all these nonverbal expressions are usually lost in the context of distance education, thus erroneously creating the impression that distance education is devoid of emotions (Vrasidas \& 
Zembylas, 2003; Jones \& Issroff, 2005; Cleveland-Innes \& Campbell, 2012). Tait (2000) referring to the support that learners should take in distance learning programs claims that it should consist of three main functions: (a) cognitive, referred to the support and development of learning, (b) the systemic, through the creation of appropriate administrative processes as well as information management systems and (c) emotional, through an environment that supports learners creates commitment to their obligations in the program and reinforces their self-esteem. These three functions are essential and interdependent.

Emotions are the positive or negative reactions on behalf of individuals towards every situation and they essentially represent the individuals' reactions based on their perceptions or mentality (Ortony, Clore \& Collins, 1988). According to this theory, emotions are regarded as cognitive evaluations while the emotions experienced by people depend on the point of focus in a given situation (Ortony, Clore \& Collins, 1988).

In recent years, the pedagogical research has been increasingly emphasizing on understanding emotions in relation to the process of learning while it has been strongly argued that emotion and reason are closely linked concepts and the interaction between them is considered crucial in shaping learning experiences. Emotions play a determinative role in the learning process (Baumeister, DeWall \& Zhang, 2007). So, what is the role of emotions experienced by open and distance education learners? How do these feelings affect their learning process? What is the role of tutor-counsellor in shaping their emotional state? These issues are important questions that greatly concern the field of distance education and this particular research. The answers to these questions may provide a set of data to be appropriately implemented so as to enhance distance learning process.

\section{Theoretical framework}

\section{Emotions and learning}

There is a growing interest in the impact of emotions on the learning process. Emotions dominate the human experience while constituting reactive responses on behalf of the subject (Ortony, Clore \& Collins, 1988). Understanding the nature of emotion and its impact on learning may improve the learning process since all activities and decisions require specific emotional functions (Dirkx, 2008). Given the fact that emotions are met in a wider spectrum of human experiences related to perception, it becomes obvious that they cannot be separately considered from the learning experience (Lehman, 2006). Emotions are necessary for the rational decision making and that the emotional experience shapes the decisions taken by individuals, excluding some choices while highlighting others (Damasio, 1994).

Adult educators refer to personal or emotional issues adults bring along to the educational setting as "baggage" or "barriers" to learning (Dirkx \& Spurgin, 1992). In that sense emotions are particularly important in adult education because they can either hinder or motivate learning, while emotions are approached through the creation of images involved and representing feelings as a means of interpreting the events of reality (Dirkx, 2001). Disregarding emotion in the educational process especially in the past decades is due to the dominant place held by cognitive psychology, thus resulting in exclusion or non-application of any emotion in the field of educational research (Ingleton, 2000). Emotions are erroneously considered to be hindering the effectiveness of teaching and learning (Dirkx, 2008). Their role in the learning process is deeper as emotions shape the learning and teaching experiences held by teachers and learners (Ingleton, 2000). 


\section{Distance learning and emotions}

There is a general impression that distance learning is devoid of feelings compared to the traditional education and this is mainly due to the distance between the learners and the tutorcounsellor. Recent researches suggest that this impression is not only groundless but moreover distance education is characterized by a set of positive and negative emotions that sometimes hinder or even promote the learning process (Hara \& Kling, 2000; Conrad, 2002; O'Regan, 2003; Rovai \& Wighting, 2005; Derks, 2007; Zembylas, 2008; Angelaki \& Mavroidis, 2013).

Undoubtedly, the learning processes are a key element in the educational research; nonetheless the emotional experiences held by learners are a dynamics that has been neglected in distance education (Cleveland-Innes \& Campbell, 2012). In collaborative distance learning the success or failure depends on the extent to which learners are able to pass through the feeling of alienation to the sense of community, in other words to feel part of a group with common educational goals (Wegerif, 1998). According to Henri and Rigault (1996) collaborative learning in general is a new pedagogical method which refers mainly to face-to-face situations and has gradually begun to be adopted in distance education in this new technological age. In collaborative learning individuals work towards a common objective, which requires them to define their aims to create and work towards a joined goal by sharing responsibility for the learning process (Roschelle \& Teasley, 1995).

From the work of Rice and Love (1987) who argued that distant learning appears to be less emotional and more impersonal as compared to the face-to-face communication till today, much has changed in relation to the role and influence of emotions in distance learning. Hara and Kling (2000) examined the "anxiety" felt by the learners during a distance learning course and found that the learners are interested in receiving immediate and consistent feedback throughout the course. Rovai and Wighting (2005) examined the feelings of alienation experienced by the learners and the sense of community in relation to the learners' dropout rates in a post-graduate distance program. This relation is inversely proportional thus recording the feeling of alienation and the sense of community can provide a tool of predicting the positive attitude and cohesion among learners in a distance education program (Rovai \& Wighting, 2005).

For Tait (2000), in the future, open and distance learning services to students will be defined by two interrelated trends: (a) the development of ICT (Information and Communication Technology) and the www and (b) by increasing domination of the business rather than the social environment in order to commercialize education. That of course is likely to bring changes in terms of supporting the open and distance learning students but also changes in the way of communication between student-tutor (Tait, 2000). Distance learning exhibits some unique challenges associated with this communication framework defined by the technological means (McFadden, 2005). The more the technological means develop and change, the more the communication framework between the learners and the tutor-counsellor is diversified. Therefore, for McFadden (2005) both reason and emotion should hold an equally central role in distance education as the reinforcement of the learners' positive emotions on behalf of the tutorcounsellor contributes to reducing insecurity and anxiety, strengthening the feeling of satisfaction and ultimately to enhancing the learners' participation in the educational program.

Juutinen and Saariluoma (2010) studied the emotional barriers raised in an online distancelearning program. The dominant emotions experienced by the learners were anxiety, satisfaction, disillusionment and pride. The learners' emotional state is directly related to their learning situation. What is more, the learners' unfamiliarity with the methodology of distance learning can cause disillusionment, confusion and thus decrease their interest in learning (Juutinen \& 
Saariluoma, 2010). For Derks, Fischer and Bos (2008) there is no evidence to indicate that communication in distance education triggers the learners' feelings to a lesser degree in relation to the face-to-face communication.

Emotions in distance learning may well be indirectly yet explicitly expressed and serve similar functions compared to face-to-face communication (Derks, 2007). Nevertheless, the role of emotions in distance education has been significantly neglected because of the dominant place held until now by reason concerning the acquisition of knowledge (McFadden, 2005). Martinez (2001) argues that if the dynamics of emotions is overlooked in the learning process and the focus is placed on reason and cognitive functions, it is likely that the online distance learning will become ineffective, especially when the tutor-counsellor does not facilitate the process of learning through providing motivation and support.

Innovations regarding the development of technology and its applications in distance education offer a new field for the study of emotions and learning (Cleveland-Innes \& Campbell, 2012). In fact, as claimed by O'Regan (2003), the online distance learning provides the opportunity of integrating emotions in the educational process. Therefore, the deeper and more focused is the study of emotional states experienced by the learners is, the more comprehensible are the mechanisms through which learning objectives are best achieved (O'Regan, 2003).

The emotions experienced by the learners as well as their intensity are mainly related to the methodology of distance learning and the curriculum requirements (Zembylas, 2008), while being one of the key factors for a successful relationship between the learners and the tutor-counsellor. The learner's need to express their feelings through written text is often manifested by the use of emoticons, that is to say icons created by keyboard characters, simulating some basic emotional facial expressions (Vrasidas \& Zembylas, 2003; Derks, 2007). So, emotions crucially define the way in which the learner will be adapted to the learning environment of distance education, will perceive their role and the sociability which should be developed through online educational framework and moreover the way of organizing the learning material, thus ultimately affecting the final educational outcome (Cleveland-Innes \& Campbell, 2012).

\section{Context of the Hellenic Open University (HOU)}

The HOU is the only one Greek State University that provides distance education in both undergraduate and postgraduate levels since 1998 via the development and utilization of appropriate learning material and methods of teaching. It consists of four Schools namely, Humanities, Social Sciences, Science and Technology, and Applied Arts. It offers 6 undergraduate and 27 postgraduate courses. Usually the number of applicants for a particular course far exceeds the number of places available, the selection of students is conducted by random public electronic draw.

Undergraduate students are awarded a degree upon the successful completion of twelve course modules. Postgraduate students are awarded a Masters degree upon the successful completion of four course modules and a dissertation. Module courses require four to six written assignments, according to the subject area, and are evaluated by tutor-counsellor. Written assignments are compulsory for all students and must be sent to tutor-counsellor by the due date referred on the study plans. Students participate in five face-to-face Counselling Group Sessions (CGS) during the 10 month academic year. However the CGS are not compulsory. Each CGS is coordinated by the tutor-counsellor and there are approximately 30 students per tutorial group. 
Tutor-counsellor contacts his/her students during the academic year either by email or by telephone. Such communication aims at supporting students' learning by clarifying and discussing with them the various issues related with their studies as well as assisting them in their preparation for the assignments, motivating students and discussing ways of dealing with any learning or practical difficulties they might encounter in their studying. Such tutor - student communication is complemented by five four-hour CGS that each tutor-counsellor has with his/her students. At the end of each 10 month academic year, students also take a final course module examination.

There is also a web-based instructional portal through which students can obtain information about each course. Indeed, through this portal an asynchronous interaction is enabled both between teacher and students and among students. The relation between transactional distance and autonomy in the distance learning environment of HOU is examined by Vasiloudis, Koutsouba, Giossos and Mavroidis (2015). They found that there was a change in sensitivity to others, due to the evolution of the learning process and the development of the student community (Vasiloudis, Koutsouba, Giossos \& Mavroidis, 2015).

According to Moore (1993) the transactional distance is "the universe of teacher-learner relationships that exist when learners and instructors are separated by space and/ or by time" (Moore, 1993, p.22). Transactional distance refers to the theory of cognitive space between instructors and learners in an educational setting, especially in distance learning. Generally the theory describes the relationship among variables and how these variables interact with each other. These three variables are: (a) the dialogue taking place between the teacher and the learner, (b) the structure of the educational program, and (c) the learner's autonomy (Moore, 1993).

\section{Research questions}

The aim of our research is to explore the emotions experienced by the learners of the HOU and the way they can be influenced through communication between the learners and the tutorcounsellor. So, the current study focuses on the following two research questions:

- How does the communication between the learners and the tutor-counsellor affect the learners' emotional state in the HOU?

- How do the emotions developed contribute to the learners' successful or non-successful progress in a distance education program?

\section{Methods}

\section{Sample}

The sample consisted of 122 students of the HOU. More specifically it consisted of 54 undergraduate students and 68 postgraduate students who participated in Counselling Group Sessions (CGS). Data collection was performed through a questionnaire in April 2014. Participation in the study was voluntary. Also, semi-structured interviews were conducted in which four additional post-graduate learners of the HOU participated (Miles, Huberman \& Saldaña, 2014). 


\section{Survey tools}

The research tools were a questionnaire and the semi-structured interviews. The questionnaire was initially administered to eight post-graduate learners on a pilot-basis implementation. Subsequently it was divided into four sections, comprising 23 close-ended questions and one open-ended question. Specifically, the open-ended question required that the participants report the emotions experienced most intensely during their studies but also the reasons for which they would give up their studies in the HOU.

The first part of the questionnaire referred to the participants' demographic characteristics, while the remaining three sections referred to the emotions experienced by the learners during their studies in the HOU as well as to specific factors generating these feelings such as their communication with the tutor-counsellor. In the majority of the questions, the participants had to choose via the five-point Likert scale format $(1=$ Not at all, $2=$ Little, $3=$ Moderately, $4=$ Much, $5=$ Very much). More specifically the first part of the questions dealt with the learners' demographic traits: the age, the marital status, the interviewees' employment status and their level of education as well as the Module they were attending during the research's taking place in the HOU. The second part referred to the emotions experienced by the learners concerning the methodology applied in distance learning programs and to the feeling of belonging to a group. The third part highlighted the role of communication between the tutorcounsellor and the learners and the emotions emerged. Finally, the fourth part referred to the way the learners' emotions can constitute an obstacle or conversely motivate them to complete their studies.

Regarding the emotions appearing in the questionnaire, they had to choose among five positive emotions (joy, satisfaction, enthusiasm, trust/safety and relief) and five negative emotions (stress, despair, vexation, loneliness/isolation and indignation). The selection of these particular positive and negative emotions was based on the literature review (Hara \& Kling, 2000; Conrad, 2002; O’Regan, 2003; Rovai \& Wighting, 2005; Derks, 2007; Zembylas, 2008; Angelaki \& Mavroidis, 2013). The positive and negative feelings that were involved in the questionnaire are characterized as vital both by researchers of emotions and by investigations related to the study of emotions experienced by the distance education learners.

\section{Data analysis}

The collected data from the 122 questionnaires were analyzed using the statistical software SPSS 21. In terms of data descriptive analysis, frequency tables and relative frequency tables were used as well as the mean and standard deviations. In terms of inductive analysis, parametric criteria were used such as the t-test for dependent and independent samples as well as the one-way analysis of variance (One-way ANOVA). The interviews' transcription was used to perform a content analysis (Miles, Huberman \& Saldaña, 2014).

\section{Results}

\section{Frequency and way of communication between the tutor-counsellor and the learners}

According to the learners' statements concerning the frequency rate of their contact with the tutor-counsellor beyond group consultation meetings during an academic year, it has been observed that $54.1 \%$ of the learners answered "not at all", that is to say that they communicate 13 times with the tutor-counsellor during the year, 24.6\% answered "moderately", in other words 
they communicated 4-7 times per year with the tutor-counsellor, while 15.6\% answered "much", in other words they came in contact 1-2 times per month with the tutor-counsellor.

Similar findings were obtained from the interviewees' statements, who reported that their communication with the tutor-counsellor was quite limited or at least not as frequent as they wished. It is characteristic that some of the interviewees stated that at the beginning of their academic program in the HOU they felt more reluctant and embarrassed in their communication with the tutor-counsellor and for this reason they did not assumed the initiative to communicate. Nonetheless, the more their experience and familiarity with the methodology of the distance education increased, the more comfortably they felt in coming in contact with their tutorcounsellor. However, the total of the interviewees said that the positive attitude on behalf of the tutor-counsellor during their communication was crucial to trigger the need for further communication.

Regarding communication methods chosen by the learners to come into contact with the tutorcounsellor, the following order of priority occurred via:

- email,

- personal contact with the tutor-counsellor,

- telephone,

- the platform of the HOU and

- rarely via Forums.

Concerning other ways of communicating with the tutor-counsellor, it seems that they are not at all used. Particularly, communication via Skype has been depicted with a mean of 1.09, communication via chats with a mean of 1.05 and via teleconference with a mean of 1.03 .

\section{Learners' emotions through their communication with the tutor-counsellor}

Regarding communication between the learners and the tutor-counsellor, it occurred that the learners are motivated mainly by negative emotions in their decision to contact the tutorcounsellor. Specifically, stress is the dominant negative emotion that pushes learners to communicate with the tutor-counsellor with a percentage of $73.8 \%$, while it is impressive that about half of them $(50.8 \%)$ support that the feeling of despair is the primary reason for communicating with the tutor-counsellor. Indeed, the positive emotions are shown not to be capable of creating the need for communication between the learners and the tutor-counsellor. It was observed that the learners chose the emotions of joy with a percentage of $55.8 \%$, satisfaction with $54.1 \%$, enthusiasm with $62.03 \%$ and relief with $54.9 \%$ as being able to push them to communicate with the tutor-counsellor varying from "rarely" to "a little". It is also characteristic that the feeling of trust/safety was chosen by $56.6 \%$ of the learners as being able to push them into contact with the tutor-counsellor.

Through the t-test, the shift of emotions that force the learners of the $1^{\text {st }}$ Module and the $4^{\text {th }}$ Module to communicate with the tutor-counsellor was analysed. In particular, the emotions of joy, satisfaction, stress and isolation were examined. The difference in the emotions-motives of communication is statistically significant $(\mathrm{t}(34)=-2.987, \mathrm{p}<.05)$ concerning the learners both of the $1^{\text {st }}$ Module and the $4^{\text {th }}$ Module, but this only concerned the feeling of loneliness/ isolation which appeared to be the most important factor of promoting communication between the learners of the $4^{\text {th }}$ thematic unit with the tutor-counsellor. 
Furthermore, the shift of the learners' emotions before and after contact with the tutorcounsellor was examined. By using the t-test for dependent samples it was found that there is a statistically significant difference in the mean values of the learners' responses regarding their positive emotions, $(\mathrm{t}(121)=-12.958, \mathrm{p}<.05)$, before and after contact with the tutor-counsellor (Table 1).

Table 1: Learners' positive feelings before and after communication with the tutor-counsellor

\begin{tabular}{llcccc}
\hline & $\mathrm{M}$ & $\mathrm{SD}$ & $\mathrm{t}$ & $\mathrm{P}$ \\
\hline Po which extent do you hold positive feelings & $\begin{array}{l}\text { lofore communicating with the tutor-counsellor? } \\
\text { befor } \\
\begin{array}{l}\text { To which extent do you hold positive feelings after } \\
\text { communicating with the tutor-counsellor? }\end{array}\end{array}$ & 2.4475 & 1.11461 & & \\
\hline
\end{tabular}

Correspondingly, it was found that there is a statistically significant difference in the mean values of the learners' responses regarding their negative feelings, $(t(121)=9.990, \mathrm{p}<.05)$, before and after communication with the tutor-counsellor. In other words, the effect of communication between the learners and the tutor-counsellor is statistically significant in the shift of their emotions (Table 2).

Table 2: Learners' negative feelings before and after communication with the tutor-counsellor

\begin{tabular}{llcccc}
\hline & $\mathrm{M}$ & $\mathrm{SD}$ & $\mathrm{t}$ & $\mathrm{P}$ \\
\hline Po which extent do you hold negative feelings before & 2.1967 & 1.02400 & & \\
Pair 2 & $\begin{array}{l}\text { communicating with the tutor-counsellor? } \\
\begin{array}{l}\text { To which extent do you hold negative feelings after } \\
\text { communicating with the tutor-counsellor? }\end{array}\end{array}$ & 1.4672 & .69881 & 9.990 & .000 \\
\hline
\end{tabular}

In particular, it seems that there has been an improvement of the learners' emotional state after their communication with the tutor-counsellor. Their positive emotions "increase" (the mean value increases from 2.5 to 3.6) whereas the negative emotions "decrease" (the mean value decreases from 2.2 to 1.5$)$.

\section{Impact of emotions and of the role of tutor-counsellor}

The contribution of the communicative role held by tutor-counsellor in the completion of the learners' studies, according to their answers, seemed to be of crucial importance. Specifically, $84.4 \%$ of the learners from "moderately" to "very much" claim that communication with the tutor-counsellor plays an important role during the course and completion of their studies. Only two learners of the total of 122 respondents answered that their communication with the tutorcounsellor had no effect on the course and completion of their studies.

The learners consider that all five positive emotions (joy, satisfaction, enthusiasm, trust/safety, relief) may be the motivating factors for the completion of their studies (Table 3). Indeed, the feeling that seems to have a vital role in their decision to complete their studies is that of satisfaction $(\mathrm{M}=4.37, \mathrm{SD}=.78)$ and then enthusiasm $(\mathrm{M}=4.08, \mathrm{SD}=1.05)$ and trust $/$ safety $(\mathrm{M}=4.02, \mathrm{SD}=1.10)$ follow. 
Table 3: Positive feelings that may be the motivating factors for the completion of the learners' studies

\begin{tabular}{lcc}
\hline Positive feelings & $\mathrm{M}$ & $\mathrm{SD}$ \\
\hline Joy & 3.89 & 1.10 \\
Satisfaction & 4.37 & .78 \\
Enthusiasm & 4.08 & 1.05 \\
Trust/Safety & 4.02 & 1.10 \\
Relief & 3.88 & 1.13 \\
\hline
\end{tabular}

Regarding the five negative emotions (stress, despair, vexation, loneliness/alienation, indignation) and according to the learners' claims, they can hinder the course and completion of their studies (Table 4). Specifically, stress $(\mathrm{M}=4.04, \mathrm{SD}=1.23)$ is the most intense negative emotion that can not only be an obstacle to the completion of their studies, but it also appears to lead them even to give up their studies.

Table 4: Negative feelings that may hinder the completion of the learners' studies

\begin{tabular}{lcc}
\hline Negative feelings & $\mathrm{M}$ & $\mathrm{SD}$ \\
\hline Stress & 4.04 & 1.23 \\
Despair & 3.40 & 1.51 \\
Vexation & 3.30 & 1.40 \\
Loneliness/Alienation & 3.02 & 1.58 \\
Indignation & 3.02 & 1.62 \\
\hline
\end{tabular}

It is worth noting that $22 \%$ of the respondents mentioned that there was a moment at which they felt the need to give up their studies. Referring to the reasons that led them to this point, the following axes emerged:

- Axis 1: negative emotions;

- Axis 2: lack of communication with the tutor-counsellor and lack of communicability by the latter;

- Axis 3: family, professional and economic reasons.

Specifically with respect to the first axis the negative feelings reported by the participants in our research were stress, despair, disillusionment, vexation and indignation. Stress seemed to dominate once again, reported by $52 \%$ of the learners The answers of some learners are very strikingly interesting: "Stress made me feel that I give up", "Stress, vexation and indignation derived from a tutor-counsellor's behaviour who dented the post-graduate learners' self-esteem", "Excessive stress due to completing the paper in the course Educational Research in Action".

Regarding the second axis, the lack of communication with the tutor-counsellor and the lack of communicability are reported by learners as key reasons that would lead them to the brink of abandoning their studies in the HOU. Some learners also mentioned: "Poor communication with the tutor-counsellor, strict grading of assignments, lack of communicability and knowledge on behalf of the tutor-counsellor", "Stress, despair, failure to coordinate with the program requirements, lack of communication with the tutor-counsellor", "Disillusionment due to lack of communicability and knowledge on behalf of the tutor-counsellor".

Regarding the third axis, the family, professional and economic reasons are mentioned as factors which motivate learners to give up their studies. These factors, according to the learners' answers are directly linked to the lack of time available and the psychological pressure they experience. It has been characteristically reported: "Economic reasons, workload", "Lack of time due to family commitments", "Professional and family obligations", "Economic, family problems and 
psychological distress", "Psychological pressure, lack of time, financial condition" are the basic causes that would push them to permanently give up their studies.

\section{Discussion and conclusions}

The first research question refers to the communication between the learners and the tutorcounsellor as well as to the communicative role to be held by the tutor-counsellor in HOU. The learners, apart from the CGS, seem not to have frequent communication with the tutorcounsellor. Most learners communicate 1-3 times a year, while a smaller percentage communicates 4-7 times a year with the tutor-counsellor primarily via email. Generally, learners are reluctant to come in contact with the tutor-counsellor as reported by Angelaki and Mavroidis (2013).

Nevertheless, it was observed that the learners strongly seek face-to-face communication with the tutor-counsellor and therefore they try to attend the group consultation meetings. Through faceto-face communication, the learners take immediate feedback from the tutor-counsellor, while experiencing a climate of trust and safety. Highlighting the role of tutor-counsellor in creating a climate of trust, safety and pleasure, Conrad (2002) emphasizes the need for adequate guidance and communication to be fostered between the learners and the tutor-counsellor. This conclusion is also consistent with the assertions of Hara and Kling (2000), who report that the learners need immediate feedback, hence they show their preference to face-to-face communication. The social role of the tutor-counsellor is highlighted by Jones and Issroff (2005), who point out that he/she contributes to the social relevance and serves as a means of enhancing the learning process and learning outcomes.

Our research revealed, mainly through the interview data, the need to strengthen the role of tutor-counsellor through the skill of providing psychological and emotional support to the distance learners. Therefore, his cognitive level but also the ability to recognize the learners' emotional and psychological state and contribute to the promotion of their positive emotions was considered to be incredibly significant. Similarly, the ability of the tutor-counsellor to recognize the learners' emotional shift has been mentioned by McFadden (2005). It was also found out that the learners are urged to communicate with the tutor-counsellor mainly by negative emotions with stress, loneliness/alienation and despair dominating. The learners, upon coming in contact with the tutor-counsellor, feel satisfaction and less stress. In contrast, positive emotions are an inhibitory factor in their communication as it is also mentioned by Angelaki and Mavroidis (2013).

The second research question refers to the feelings and the factors that contribute to the learners' successful or unsuccessful participation and attendance in the distance learning program. Negative emotions experienced by the learners during their studies in the HOU seem to play an important role in the course and completion of their studies as they emerge as emotional barriers, which are stress, despair, disillusionment, vexation and indignation. Regarding the positive feelings, the learners argue that they constitute an incentive for the smooth course of their studies. The positive emotions that lead to the corresponding positive learning outcomes but also the negative emotions that are responsible for negative learning outcomes also reported by Baumeister, DeWall and Zhang (2007).

Learners' feedback and support on behalf of the tutor-counsellor can prevent any dropouts and enhance their participation and attendance in the program according to the research held by McFadden (2005). So, the absence of essential communication between learners and tutorcounsellor and the lack of communicability fosters negative emotions. The difficulties and the workload encountered by the learners when writing their assignments combined with family, 
professional and financial obligations are additional factors that may push them to abandon their studies. Comparing the responses by male and female students, it was observed that the latter appeared more anxious mainly because of particular social, family and business challenges that they face daily. Therefore, it is observed that the effect of emotions is ubiquitous in all stages of the learners' education. They appear at their first contact with the setting of distance learning, they change depending on the quality of communication between the learners and the tutorcounsellor and influence the choices and the progress of their studies.

Our research confirms the essential role played by emotions in distance education. The dynamics of emotions in distance education should be thoroughly examined and the data emerged be seriously taken both for the establishment of a revised theoretical framework about the relationship between emotions and distance learning as for the implementation of this framework in the educational process.

\section{References}

1. Angelaki, C., \& Mavroidis, I. (2013). Communication and social presence: The impact on adult learners' emotion in distance learning. European Journal of Open, Distance and E-Learning, 16(1), 78-93. Retrieved on February 19, 2015, from http:/ www.eurodl.org/index.php?p=archives\&year $=2013 \&$ halfyear $=1 \&$ article $=563$

2. Baumeister, R.F., DeWall, C.N., \& Zhang, L. (2007). Do emotions improve or hinder the decision making process? In K.D. Vohs, R.F. Baumeister, \& G. Loewenstein (Eds.), Do emotions help or burt decision making? A hedgefoxian perspective (pp. 11-31). New York: Russell Sage.

3. Berenson, R., Boyles, G., \& Weaver, A. (2008). Emotional intelligence as a predictor of success in online learning. The international review of research in open and distance learning, 9(2), 1-17. Retrieved on Mars 10, 2015 from http:// files.eric.ed.gov/fulltext/EJ801091.pdf

4. Cleveland-Innes, M., \& Campbell, P. (2012). Emotional presence, learning, and the online learning environment. The international review of research in open and distance learning, 13(4), 269292.

5. Conrad, D. (2002). Engagement, excitement, anxiety and fear. Learners' experiences of starting an online course. The American Journal of Distance Education, 16(4), 205-226.

6. Damasio, A. (1994). Descartes' error: emotions, reason, and the buman brain. New York: Avon Books.

7. Derks, D. (2007). Exploring the Missing Wink: Emoticons in Cyberspace. Dissertation. Open University, The Nederlands.

8. Derks, D., Fischer, A.H., \& Bos, A.E.R. (2008). The role of emotion in computer-mediated communication: A review. Computer Human Behavior, 24(3), 766-785.

9. Dirkx, J.M. (2001). The power of feelings: Emotion, and the construction of meaning in adult learning. New Directions for Adult and Continuing Education, 2001(89), 63-72.

10. Dirkx, J.M. (2008). The meaning and role of emotions in adult learning. New Directions for Adult and Continuing Education, 2008(120), 7-18.

11. Dirkx, J.M., \& Spurgin, M.E. (1992). Implicit theories of adult basic education teachers: How their beliefs about students shape classroom practice. Adult basic education, 2(1), 20-41.

12. Hara, N., \& Kling, R. (2000). Students' distress with a web-based distance education course. Information, Communication and Society, 3(4), 557-579. 
13. Henri, F., \& Rigault, C.R. (1996). Collaborative distance learning and computer conferencing. In T. Liao (Ed.), Advanced educational technology: Research issues and future potential (pp. 45-76), Berlin: Springer-Verlag.

14. Holcomb, L.B., King, F.B., \& Brown, S.W. (2004). Student Traits and Attributes Contributing to Success in Online Courses: Evaluation of University Online Courses. The Journal of Interactive Online Learning, 2(3), 1-17. Retrieved on January 15, 2015 from http://www.ncolr.org/jiol/issues/PDF/2.3.4.pdf

15. Ingleton, C. (2000). Emotion in learning - a neglected dynamic. In R. James, J. Milton \& R. Gabb (Eds.), Research and development in higher education of Comerstones of Higher Education (Vol. 22, pp. 86-99). Melbourne: Research and Development Society of Australasia.

16. Jones, A., \& Issroff, K. (2005). Learning technologies: Affective and social issues in computer-supported collaborative learning. Computers \& Education, 44(4), 395-408.

17. Juutinen, S., \& Saariluoma, P. (2010). Emotional obstacles for e-learning - a user psychological analysis. European Journal of Open, Distance and E-Learning, 13(1). Retrieved on December 12, 2014 from http:/ / www.eurodl.org/index.php?p=archives\&year $=2010 \&$ halfyear $=1 \&$ article $=402$

18. Lehman, R. (2006). The role of emotion in creating instructor and learner presence in the distance experience. Journal of Cognitive Affective Learning, 2(2), 12-26.

19. Martinez, M. (2001). Key design considerations for personalized learning on the Web. Educational Technology and Society, 4(1), 26-40.

20. McFadden, R. (2005). Souls in ice. Incorporating emotion in wed-based education. Journal of Technology in Human Services, 23(1/2), 79-98.

21. Miles, M., Huberman, M., \& Saldaña, J. (2014). Qualitative data analysis: A methods source book. Sage Publications, Thousand Oaks.

22. Moore, M.G. (1993). Theory of transactional distance. In D. Keegan (Ed.), Theoretical principles of distance education (pp. 22-38). New York: Routledge.

23. O’ Regan, K. (2003). Emotion and e-learning. Journal of Asynchronous Learning Networks, 7(3), 78-92.

24. Ortony, A., Clore, G., \& Collins, A. (1988). The cognitive structure of emotions. New York: Cambridge University Press.

25. Rice, R., \& Love, G. (1987). Electronic emotion. Communication Research, 14(1), 85-108. Retrieved on January 20, 2015 from http://www.comm.ucsb.edu/faculty/rrice/a22.htm

26. Roschelle, J., \& Teasley, S. (1995). The construction of shared knowledge in collaborative problem solving. In C.E. O’Malley (Ed.), Computer supported collaborative learning (pp. 69-97). Heidelberg: Springer-Verlag.

27. Rovai, A., \& Wighting, M. (2005). Feelings of alienation and community among higher education students in a virtual classroom. Internet and Higher Education, 8(2005), 97-110.

28. Tait, A. (2000). Planning student support for Open and Distance Learning. Open Learning 15(3), 287-299.

29. Vasiloudis, G., Koutsouba, M., Giossos, Y., \& Mavroidis, I. (2015). Transactional Distance and Autonomy in a Distance Learning Environment. European Journal of Open, Distance and eLearning, 18(1), 114-122. Retrieved on December 7, 2015 from http:/ / www.eurodl.org $/ \mathrm{p}=$ archives\&year $=2015$ \&halfyear $=1 \&$ article $=687$ 
30. Vrasidas, C., \& Zembylas, M. (2003). The nature of cross-cultural technology-mediated communication in globalized distance education. International Journal of Training and Development, 7(4), 271-286.

31. Wegerif, R. (1998). The social dimension of asynchronous learning networks. Journal of Asynchronous Learning Networks, 2(1), 34-49.

32. Wosnitza, M., \& Volet, S. (2005). Origin, direction and impact of emotions in social online learning. Learning and Instruction, 15(5), 449-464.

33. Zembylas, M. (2008). Adult learners' emotions in online learning. Distance Education, 29(1), 71 87. 